\title{
Technical note: Evaluation of a low-cost evaporation protection method for portable water samplers
}

\author{
Jana von Freyberg ${ }^{1,2,3}$, Julia L. A. Knapp ${ }^{1,4} \star$, Andrea Rücker ${ }^{1,2}$, Bjørn Studer ${ }^{1}$, and James W. Kirchner ${ }^{1,2,5}$ \\ ${ }^{1}$ Department of Environmental Systems Science, ETHZ, 8092 Zurich, Switzerland \\ ${ }^{2}$ Mountain Hydrology and Mass Movements, Swiss Federal Institute for Forest, \\ Snow and Landscape Research (WSL), 8903 Birmensdorf, Switzerland \\ ${ }^{3}$ School of Architecture, Civil and Environmental Engineering, EPFL, 1015 Lausanne, Switzerland \\ ${ }^{4}$ Department of Earth Sciences, Durham University, Durham DH1 3LE, UK \\ ${ }^{5}$ Department of Earth and Planetary Science, University of California, Berkeley, CA 94720, USA \\ ॠThese authors contributed equally to this work.
}

Correspondence: Jana von Freyberg (jana.vonfreyberg@epfl.ch) and Julia L. A. Knapp (julia.l.knapp@ durham.ac.uk)

Received: 2 July 2020 - Discussion started: 14 July 2020

Revised: 27 September 2020 - Accepted: 13 October 2020 - Published: 8 December 2020

\begin{abstract}
Automated field sampling of streamwater or precipitation for subsequent analysis of stable water isotopes $\left({ }^{2} \mathrm{H}\right.$ and $\left.{ }^{18} \mathrm{O}\right)$ is often conducted with off-the-shelf automated samplers. However, when water samples are stored in the field for days and weeks in open bottles inside autosamplers, their isotopic signatures can be altered by evaporative fractionation and vapor mixing. We therefore designed an evaporation protection method which modifies autosampler bottles using a syringe housing and silicone tube, and we tested whether this method reduces evaporative fractionation and vapor mixing in water samples stored for up to $24 \mathrm{~d}$ in 6712 full-size portable samplers (Teledyne ISCO, Lincoln, USA). Laboratory and field tests under different temperature and humidity conditions showed that water samples in bottles with evaporation protection were far less altered by evaporative fractionation and vapor mixing than samples in conventional open bottles. Our design is a cost-efficient approach to upgrade the $1 \mathrm{~L}$ sample bottles of the ISCO autosamplers, allowing secure water sample collection in warm and dry environments. Our design can be readily adapted (e.g., by using a different syringe size) to fit the bottles used by many other field autosamplers.
\end{abstract}

\section{Introduction}

The stable water isotopes deuterium $\left({ }^{2} \mathrm{H}\right)$ and oxygen-18 $\left({ }^{18} \mathrm{O}\right)$ are used as natural tracers for water flow through the landscape and thus provide important insights into water sources, flowpaths, and travel times in hydrologic systems (e.g., Gat et al., 2001; Kendall and McDonnell, 1998; Klaus and McDonnell, 2013; McGuire and McDonnell, 2008). Furthermore, deuterium and oxygen-18 signatures in precipitation and/or streamwater can help to track the movement of atmospheric air masses (Fischer et al., 2017), identify the water sources of plants (Dawson and Ehleringer, 1991), and reconstruct climate records (Shanley et al., 1998). Long-term data sets of stable water isotopes in precipitation and streamwater are available from global monitoring networks (the Global Network of Isotopes in Precipitation, GNIP, and the Global Network of Isotopes in Rivers, GNIR) and various national monitoring networks (e.g., the ISOT monitoring program of the Swiss Federal Office for the Environment).

Streamwater is usually collected through instantaneous grab sampling, after which the sample containers are sealed and cooled until laboratory analysis. In contrast, precipitation is usually collected over periods of weeks to months with open buckets or funnels mounted onto sample bottles. To prevent evaporative fractionation of the precipitation sample during the sampling period, paraffin oil can be used that 
forms a protective layer of oil floating on the water sample (IAEA, 2014; Williams et al., 2018). However, residual oil in the water sample can alter subsequent laser spectroscopy measurements (Gröning et al., 2012). The contamination risk is particularly high if the sample volume is small, so the addition of oil is only suitable for longer sampling durations (weekly or monthly) but not recommended for daily or subdaily sampling. Alternative mechanical evaporation protection modifications have been suggested, like covering the water surface with Styrofoam beads (Angermann et al., 2017) or placing a table tennis ball in the collection funnel ("ball-infunnel") to seal the inflow during times without precipitation (Prechsl et al., 2014). Another widely used collector modification is the "tube-dip-in-water" collector (Gröning et al., 2012; IAEA, 2002), where the collection bottle is sealed except for a small-diameter tube that reaches from the bottom outlet of the funnel into the water sample; this setup substantially reduces the contact area between the water sample and the atmosphere. While some of these modifications may reduce evaporative fractionation of the water sample in the bottle, others were found to be less effective (Michelsen et al., 2018; Terzer et al., 2016).

The above methods and modifications were originally designed for single-sample collection using a precipitation totalizer (e.g., IAEA, 2014). For many hydrological questions, however, higher-frequency measurements of stable water isotopes are of interest, requiring daily or even sub-daily sampling of precipitation or streamwater (e.g., Knapp et al., 2019; Rücker et al., 2019; von Freyberg et al., 2018; Wang et al., 2019). This can be achieved with field-deployable automatic water samplers with programmable pump-anddistribution systems that fill and store a series of empty open bottles. Many hydrologic studies use off-the-shelf automatic water samplers (available from, e.g., Teledyne ISCO, Lincoln (NE), USA, and Maxx GmbH, Rangendingen, Germany), because these systems are rugged, robust, versatile, and easy to program. For automatic samplers with a 24bottle configuration, this setup reduces the manual labor of daily precipitation sampling to the collection of sample bottles only once every $24 \mathrm{~d}$. However, because the sample bottles remain open during the sampling period, vapor exchange may occur between the sample water and the atmosphere inside the autosampler housing, which may alter the isotopic compositions of the water samples in the bottles (Williams et al., 2018).

While attempts have been made to design more sophisticated field-deployable, programmable water samplers which reduce these isotope fractionation effects, most of these devices are not readily available (i.e., prototypes) or are technically complex or expensive (Ankor et al., 2019; Berman et al., 2009; Hartmann et al., 2018; Michelsen et al., 2019). We therefore designed and tested a low-cost evaporation protection modification that can be used with Teledyne ISCO's 6712 full-size portable samplers and 1 L ISCO sample bottles. We retrofitted the bottles with a simplified "tube-dip-in- water" collector type that allows rapid sample flow but reduces isotope effects due to vapor exchange. The proposed setup is cheap, easy to handle, and suitable for a wide range of sample volumes that are common in daily precipitation or streamwater sampling.

\section{Methods}

\subsection{Evaporation protection}

We designed an evaporation protection modification for the $1 \mathrm{~L}$ sample bottles of the 6712 full-size portable sampler (Teledyne ISCO, Lincoln, USA; hereafter referred to as "ISCO autosampler"). The presented evaporation protection consists of a $100 \mathrm{~mL}$ syringe housing (i.e., BP Plastipak ${ }^{\mathrm{TM}}$ $100 \mathrm{~mL}$ syringe with catheter tip, without its piston and rubber piston stopper) with attached Luer tip adapter (BP Plastipak $\left.^{\mathrm{TM}}\right)$. On the Luer tip, we fit a $1 \mathrm{~mm}$ inner diameter silicone tube of approximately $9 \mathrm{~cm}$ length to reach below the water level of the sample in the bottle (Fig. 1a and b). The barrel flange of the syringe housing is trimmed on one side (Fig. 1a) to allow the retrofitted sample bottles to properly fit into the bottom compartment of the ISCO autosampler. This modified syringe housing is then plugged into the opening of an ISCO sample bottle (Fig. 1b). Because a small gap remains between the syringe housing and the inner rim of the sampler bottle opening (i.e., not air-tight), pressure differences due to water flowing into the bottle will equilibrate with the outside conditions. Thus our system does not require an external tube for pressure equilibration, such as the "tubedip-in-water collector" proposed by Gröning et al. (2012). Because the end of the silicone tube is fully immersed in the sample liquid, only the cross-sectional area of the silicone tube is exposed to the ambient atmosphere (rather than the entire cross-sectional area of the water surface), minimizing vapor exchange with the surrounding atmosphere. The presented design of the evaporation-protected ISCO bottle ensures a smooth, splash-free sample flow from the syringe through the silicone tube into the bottle when filled at a flow rate of approximately $100 \mathrm{~mL} \mathrm{~min}^{-1}$. Furthermore, it is robust, cheap ( $<$ USD 5 per sample bottle), chemically inert, and easy to disassemble and to clean.

In field operation for the collection of streamwater samples, the autosampler should be programmed to not exceed the filling rate that can be accommodated by the narrow silicone tube. This can be accomplished by programming the autosampler to deliver a series of $100 \mathrm{~mL}$ aliquots, allowing enough time between them (about 1 min minimum) so that they can drain from the $100 \mathrm{~mL}$ syringe into the sample bottle. If possible, one should also limit the total sample volume so that the water line is somewhere in the narrow silicone tube and not in the syringe, in order to limit the water surface that is available for evaporation or condensation. In order to prevent debris (e.g., sediment, insects, leaves) from 

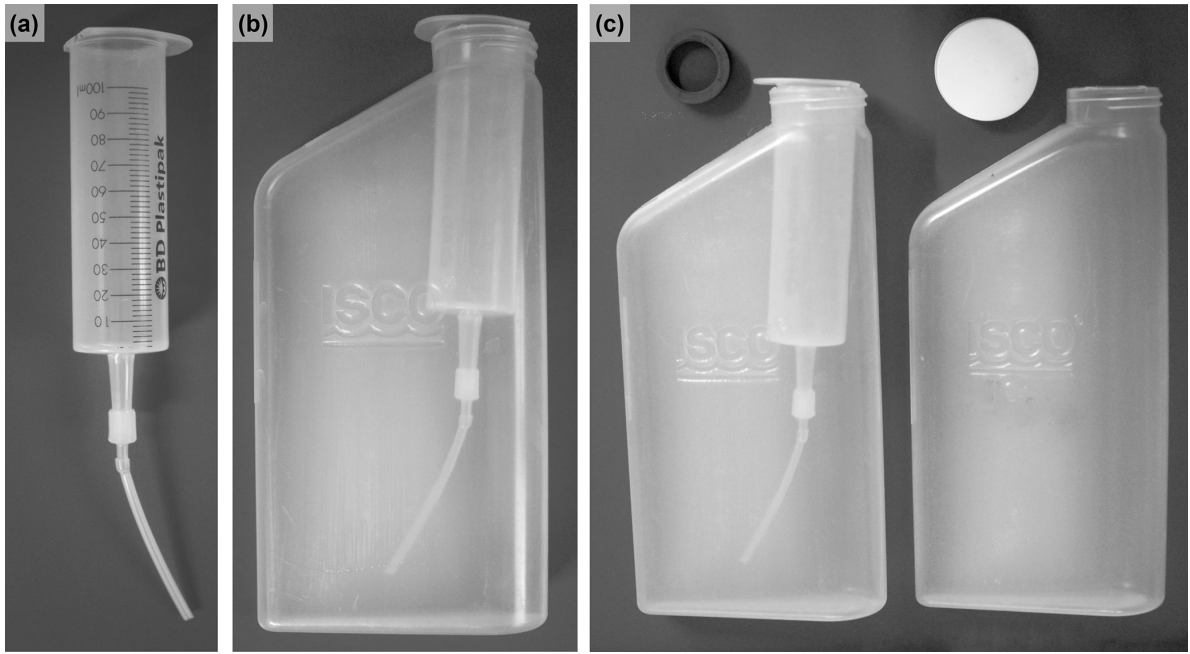

Figure 1. (a) Modified $100 \mathrm{~mL}$ syringe housing with Luer-tip adapter and fitted silicone tubing for extending the syringe outlet towards the bottom of the bottle; the barrel flange at the syringe housing was trimmed on the outer side to ensure the retrofitted bottles fit into the autosampler. (b) Retrofitted sample bottles with evaporation protection using the modified syringe shown in (a). (c) The sample bottles with evaporation protection can be sealed for transport with black rubber piston stoppers (left); bottles without evaporation protection can be sealed with a screw lid (right).

clogging the evaporation protection system, the streamwater intake or precipitation funnel can additionally be equipped with a screen. To transport the filled sample bottles, the syringe housing has to be removed and the bottles have to be sealed with screw caps supplied by the manufacturer. If the bottles are transported upright and leakage is unlikely to occur, the syringe housing can also stay in place and its upper opening can be sealed with the black rubber piston stoppers that are supplied together with the syringes (BP Plastipak ${ }^{\mathrm{TM}}$ $100 \mathrm{~mL}$ syringe with catheter tip; Fig. 1c).

\subsection{Monitoring evaporation and fractionation}

We conducted three experiments to assess the effects of evaporation and vapor mixing on the isotopic composition of the liquid samples in ISCO 6712 autosamplers, comparing the retrofitted ISCO bottles to unmodified ISCO bottles. In Experiment 1 , we simulated a daily sampling routine under extremely dry and warm conditions to test for evaporative fractionation effects over different storage durations. In Experiment 2, we used two contrasting reference waters to test for changes in their isotopic compositions due to vapor transfer between samples, in addition to fractionation effects under ambient conditions with diurnal fluctuations in temperature and humidity. Experiment 3 evaluated the performance of the retrofitted ISCO bottles during 61 two-to-three-week cycles over a nearly 4-year deployment at two field sites in the northern Swiss pre-Alps.

\subsubsection{Experiment 1}

We prepared one ISCO autosampler for a $24 \mathrm{~d}$ test of the retrofitted bottles under controlled laboratory conditions. The autosampler contained 24 sample bottles, of which 12 were retrofitted with the modified syringe housing and the other 12 bottles remained open (i.e., as they do in normal operation). Open and retrofitted bottles were arranged alternatingly in the autosampler carousel. The ISCO autosampler was placed on a heater inside a ventilated chamber where the conditions were kept at approximately $35^{\circ} \mathrm{C}$ air temperature and $11 \%$ relative humidity. Air temperature and relative humidity were measured every hour in the ventilated chamber and inside the bottom compartment of the ISCO autosampler with RHT30 humidity-temperature loggers (EXTECH Instruments, FLIR Commercial Systems Inc., Nashua, USA; measurement accuracy $\pm 1 \%$ relative humidity and $0.5^{\circ} \mathrm{C}$ temperature).

The bottom compartment (containing the sample bottles) and the middle compartment (containing the pump and control unit) of the ISCO autosampler remained attached for the entire duration of the experiment. The water samples were distributed among the bottles by using the instruments' software to move the distributor arm to the desired position. The instrument's sampling tube was not threaded through the peristaltic pump but instead was directly attached to the inlet of the distributor arm. This setup allowed us to pour an exact volume of water into the sampling tube, with the water flowing gravitationally through the distributor arm into the sample bottle (we bypassed the peristaltic pump because it does not allow such exact sample dosing and might introduce air bubbles into the sample during pumping). This sampling pro- 
tocol is consistent with the automated sampling of precipitation under field conditions, when the autosampler's sample inlet tube is connected directly to a precipitation collection funnel (i.e., bypassing the peristaltic pump) so that incoming precipitation flows directly through the distributor arm towards the pre-programmed bottle position (e.g., Rücker et al., 2018).

To ensure that the initial isotopic compositions of all water samples were comparable, we filled a $20 \mathrm{~L}$ tank with distilled reference water before the beginning of the monitoring period. This reference water tank was tightly sealed and stored at room temperature. It was only opened every second day to retrieve $801.5 \mathrm{~mL}$ of reference water. From this aliquot, $1.5 \mathrm{~mL}$ was filled into a glass vial with screw cap (screw thread vials $1.5 \mathrm{~mL}$, PP-screw thread caps with silicone/PTFE septum, WICOM Germany GmbH, Heppenheim, Germany) and stored at $4{ }^{\circ} \mathrm{C}$ until isotope analysis. The purpose of these samples was to monitor the isotopic composition of the reference water and account for possible fractionation inside the storage tank. The remaining $800 \mathrm{~mL}$ of reference water was filled into two empty ISCO sample bottles $(400 \mathrm{~mL}$ each into an open and a retrofitted bottle). For the open bottle, $400 \mathrm{~mL}$ was emptied rapidly into the inlet tube. Because of the small tubing diameter in the retrofitted sample bottles, we poured the $400 \mathrm{~mL}$ of reference water into the inlet tube in four steps of $100 \mathrm{~mL} \mathrm{~min}^{-1}$ to prevent overflow. Starting on day 1 and then every second day, one open and one retrofitted bottle were filled with $400 \mathrm{~mL}$ of reference water each following the protocol described above, and the last two sample bottles (no. 23 and 24) were filled on the 23rd day.

To monitor evaporation and isotopic fractionation under ambient conditions outside the ISCO autosampler, we prepared three additional ISCO bottles at the start of the monitoring period. For this purpose, we filled $400 \mathrm{~mL}$ of the reference water each into one open ISCO bottle (i.e., nonmodified), one ISCO bottle that was retrofitted with evaporation protection, and one tightly sealed ISCO bottle on day 1 of the laboratory experiment. We placed these bottles on the heater inside the ventilated chamber, but outside the ISCO autosampler, for the duration of the experiment (24d).

To mimic the field protocol (see Sect. 2.3), all sample bottles (i.e., inside and outside of the ISCO autosampler) were opened and sub-sampled at the end of day 24. For this, $1.5 \mathrm{~mL}$ of water from each sample bottle was immediately transferred into glass vials with screw caps and stored at $4{ }^{\circ} \mathrm{C}$ until isotope analysis.

\subsubsection{Experiment 2}

For Experiment 2, we prepared two ISCO autosamplers with alternating open and retrofitted bottles, analogously to Experiment 1 . One sampler was stored indoors at approximately constant temperature and relative humidity, and the other sampler was stored outdoors at a sunny location where ambi- ent conditions were more variable. Temperature and relative humidity were monitored inside and outside the ISCO autosamplers at both locations.

We filled all sample bottles on day 1 of the experiment to ensure that all samples underwent the same mixing and fractionation processes over the following $21 \mathrm{~d}$. We alternatingly filled the bottle pairs (open and retrofitted) with two isotopically contrasting reference waters: one, which we will call RefA, was isotopically much heavier $\left(\delta^{2} \mathrm{H} \approx-40.5 \%\right.$, $\delta^{18} \mathrm{O} \approx-5.6 \%$ ) than the other, which we will call RefB $\left(\delta^{2} \mathrm{H} \approx-69.8 \%, \delta^{18} \mathrm{O} \approx-9.7 \%\right.$ ) , with the isotopic difference between the two reference waters being approximately $29.3 \%$ and $4.1 \%$ or $\delta^{2} \mathrm{H}$ and $\delta^{18} \mathrm{O}$, respectively. To test whether smaller sample volumes were affected more substantially by vapor mixing and evaporation, we alternated the sample volumes between 200 and $400 \mathrm{~mL}$. Thus, the carousel of each ISCO autosampler contained three replicates of each possible combination of the two reference waters (RefA vs. RefB), the two sample volumes $(200 \mathrm{~mL}$ vs. $400 \mathrm{~mL})$, and the two bottle types (open vs. retrofitted with evaporation protection).

We placed four additional sample bottles into the center of each autosampler carousel on day 1 of the experiment. Two of these bottles contained $200 \mathrm{~mL}$ of RefA water, and the other two bottles contained $200 \mathrm{~mL}$ of RefB water; all four bottles were tightly sealed.

The bottom compartment of the autosampler (containing the sample bottles) and the middle compartment (containing the pump and control unit) remained attached for the entire duration of the experiment. Sample bottles were weighted at the start and end of the experiment to track potential changes in water volumes. After $21 \mathrm{~d}$, the ISCO autosamplers were opened and all bottles were retrieved. We transferred $1.5 \mathrm{~mL}$ of the liquid sample water from each bottle into glass vials with screw caps and stored them at $4{ }^{\circ} \mathrm{C}$ until isotope analysis.

\subsubsection{Experiment 3}

To assess the effectiveness of the retrofitted bottles under central European climatic conditions, we monitored evaporative fractionation in two ISCO autosamplers during 61 twoto-three-week sampling periods between October 2015 and June 2019. For this purpose, we installed the ISCO autosamplers at two different locations in the northern Swiss preAlps: at the EIN site located near the city of Einsiedeln $\left(8.75708^{\circ} \mathrm{E}, 47.13370^{\circ} \mathrm{N}\right.$; WGS84) at $910 \mathrm{~m}$ a.s.l. (above sea level) and at the ERL site located roughly $11 \mathrm{~km}$ southwest of Einsiedeln in the Erlenbach catchment $\left(8.71502^{\circ} \mathrm{E}\right.$, $47.04249^{\circ} \mathrm{N}$; WGS84) at $1228 \mathrm{~m}$ a.s.l.

At the beginning of each sampling period, we filled one tightly sealed, one open, and one retrofitted sample bottle with $400 \mathrm{~mL}$ reference water each and placed them in the center of the ISCO carousel (the outer 24 bottles were reserved for conventional automatic precipitation sampling, 
not discussed here). The ISCO autosamplers remained at the field sites for roughly $2-3$ weeks before all bottles were collected and replaced with new ones. After collecting the sample bottles, they were transported to the ETH Zurich laboratory and $1.5 \mathrm{~mL}$ of sample water was transferred from each bottle into glass vials with screw caps; the vials were stored at $4{ }^{\circ} \mathrm{C}$ until isotope analysis.

To identify potential drivers of evaporative fractionation effects during these sampling periods, we used on-site air temperature and relative humidity measurements. These measurements were provided by the Swiss Federal Office of Meteorology and Climatology (MeteoSwiss) for the EIN site and by the Swiss Federal Institute for Forest, Snow and Landscape Research (WSL) for the ERL site. In addition, we used daily maximum, minimum, and average values of air temperature and relative humidity to calculate the daily vapor pressure deficit ( $\mathrm{VPD}=e_{\mathrm{s}}-e_{\mathrm{a}}$ ) following Allen et al. (1998):

$e_{T}^{0}=0.6108 \cdot \exp \left(\frac{17.27 \cdot T}{T+237.3}\right)$,

$e_{\mathrm{S}}=\frac{e_{T_{\max }}^{0} \cdot e_{T_{\min }}^{0}}{2}$,

$e_{\mathrm{a}}=\frac{e_{T_{\min }}^{0} \cdot H_{\max }+e_{T_{\max }}^{0} \cdot H_{\min }}{2}$,

where $e_{T}^{0}$ is the saturation vapor pressure $(\mathrm{kPa})$ at the air temperature $T\left({ }^{\circ} \mathrm{C}\right), e_{\mathrm{s}}$ is the saturation vapor pressure $(\mathrm{kPa})$, $e_{\mathrm{a}}$ is the actual vapor pressure ( $\left.\mathrm{kPa}\right), H$ is the relative humidity (-), and the indices "min" and "max" indicate the minimum and maximum values of temperature and relative humidity observed during any day. To compare these potential drivers with the isotopic differences, we averaged the daily values of air temperature, humidity, and VPD over the individual sampling periods.

\subsection{Stable water isotope analysis and isotopic differences}

For Experiment 3, all water samples collected between 6 October 2015 and 13 December 2017 were analyzed at the laboratory of the Swiss Federal Institute for Forest, Snow and Landscape Research (WSL) with an LGR IWA-45-EP isotopic water analyzer (Los Gatos Research, ABB Los Gatos Research, San Jose, CA, USA) with a measurement precision of $0.5 \%$ for $\delta^{18} \mathrm{O}$ and $1 \%$ for $\delta^{2} \mathrm{H}$. All of Experiment 3's samples collected after 13 December 2017, and all water samples of Experiments 1 and 2, were analyzed with a cavity ring-down spectrometer at the ETH Zurich laboratory (L2140-i liquid isotope analyzer, Picarro Inc., Santa Clara, CA, USA) with a measurement precision of $0.2 \%$ for $\delta^{18} \mathrm{O}$ and $1 \%$ ofor $\delta^{2} \mathrm{H}$. All isotope values in this study are reported in $\delta$-notation relative to Vienna standard mean ocean water (V-SMOW), and the measurement uncertainty is provided as standard deviations calculated from 2 to 3 repeated injections of each sample.
To quantify isotopic effects in the water samples, we calculated the isotopic difference $\left(\Delta \delta^{18} \mathrm{O}\right.$ and $\Delta \delta^{2} \mathrm{H}, \%$ ) between the water sample at the end of the storage period and the reference water at the beginning of the storage period:

$\Delta \delta^{i} E=\delta^{i} E_{\text {sample }}-\delta^{i} E_{\text {reference }}$,

where $\delta^{i} E_{\text {sample }}$ and $\delta^{i} E_{\text {reference }}$ are the delta values of the isotope ${ }^{i} E$ in the sample water or the reference water, respectively. For Experiment 1, we compared the isotope composition of the water samples from the open and retrofitted bottles $\left(\delta^{2} \mathrm{H}_{\text {sample }}, \delta^{18} \mathrm{O}_{\text {sample }}\right)$ to the isotope composition of the reference water from the storage tank $\left(\delta^{2} \mathrm{H}_{\text {reference }}\right.$, $\left.\delta^{18} \mathrm{O}_{\text {reference }}\right)$. Because each second day we collected one reference water sample from the tank and filled one open and one retrofitted bottle with reference water, the comparison of the isotopic differences $\left(\Delta \delta^{i} E\right)$ of samples from bottles with and without evaporation protection assesses the effectiveness of the retrofitted sampler bottles in protecting against evaporative enrichment. For Experiment 2, we compared the isotopic composition of the RefA and RefB water samples from the various open and retrofitted bottles $\left(\delta^{2} \mathrm{H}_{\text {sample }}\right.$, $\left.\delta^{18} \mathrm{O}_{\text {sample }}\right)$ to the isotopic composition of the closed sample bottles with the corresponding reference water RefA or RefB $\left(\delta^{2} \mathrm{H}_{\text {reference }}, \delta^{18} \mathrm{O}_{\text {reference }}\right)$ in order to quantify isotope effects due to vapor mixing and evaporation. For Experiment 3, we compared the isotopic composition of water samples from the open and retrofitted bottles $\left(\delta^{2} \mathrm{H}_{\text {sample }}, \delta^{18} \mathrm{O}_{\text {sample }}\right)$ to the isotope values of the reference water in the tightly sealed bottles (i.e., $\delta^{2} \mathrm{H}_{\text {reference }}, \delta^{18} \mathrm{O}_{\text {reference }}$ ) for each sampling period.

\section{Results}

\subsection{Laboratory evaluation of the evaporation protection method: Experiment 1}

During Experiment 1, humidity outside the ISCO autosampler stayed relatively constant at approximately $11 \pm 3 \%$ (mean \pm 1 standard deviation), while it continuously increased inside the ISCO bottom compartment from $33 \%$ to $100 \%$ between day 1 and 13 and then remained at $100 \%$ until the end of the experiment (Fig. 2a). Air temperature outside the ISCO autosampler was around $35 \pm 1^{\circ} \mathrm{C}$ with distinct diurnal variations $\left(\mathrm{a} 1.2{ }^{\circ} \mathrm{C}\right.$ temperature drop at the beginning of the fourth day was caused by moving the humiditytemperature logger from a position close to the heater to a higher position near the sampler's control unit to better represent the conditions inside the ventilated chamber). The air temperature inside the ISCO housing was $36 \pm 1{ }^{\circ} \mathrm{C}$ and did not exhibit strong diurnal patterns.

The sample bottles stored outside the autosampler (i.e., at $11 \%$ relative humidity and $36^{\circ} \mathrm{C}$ temperature) experienced different degrees of evaporative fractionation between the start and end of the monitoring period (Table 1): while evaporative fractionation was insignificant in the closed bottle, 

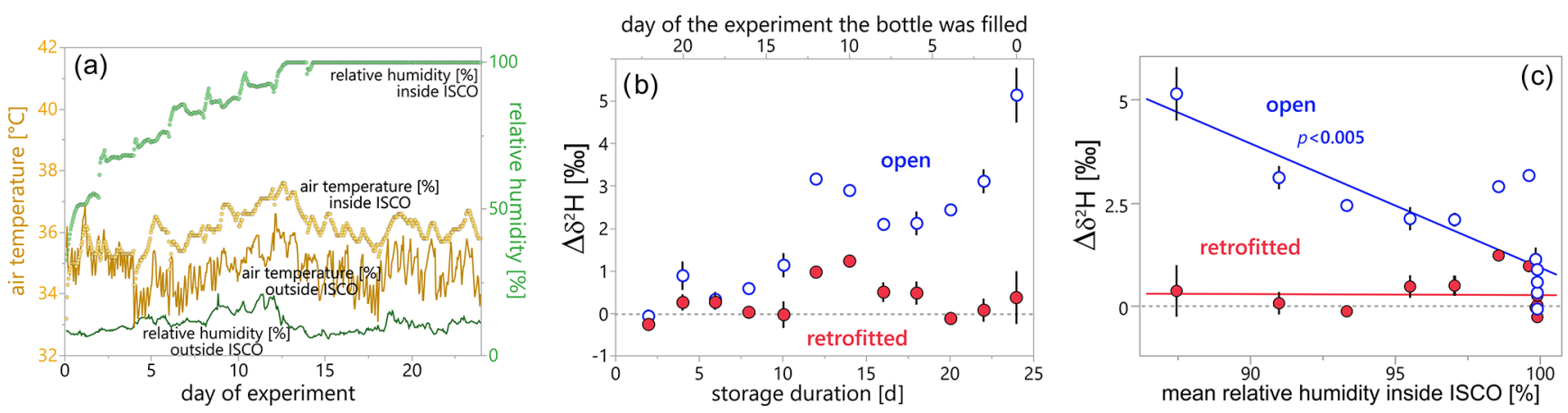

Figure 2. (a) Evolution of air temperature (yellow) and relative humidity inside (light green) and outside (dark green) the ISCO autosampler during Experiment 1 . Humidity outside the ISCO autosampler stayed relatively constant between $6 \%$ and $21 \%$, whereas humidity inside the sampler increased over time to $100 \%$. Average air temperature was similar inside and outside, but fluctuations were more pronounced outside the autosampler. (b) The isotopic enrichment of the sample water relative to the reference water (here expressed as isotopic difference $\Delta \delta^{2} \mathrm{H}$ ) was stronger for samples in open bottles (open blue circles) and increased with longer storage durations. The isotopic difference was calculated for each sample relative to the isotopic composition of the reference water in the storage tank on the day the bottle was filled (Eq. 4). (c) Isotopic difference in water samples relative to the reference water as a function of the mean relative humidity, which represents the average of relative humidity values during the full storage duration of each bottle. The linear regression (solid line) for the open bottles is statistically significant at $p<0.005$; the regression slope for the retrofitted bottles is not statistically different from zero. In (b) and (c), water samples in open bottles are marked with blue open circles, whereas water samples in retrofitted bottles are marked with red filled circles. Error bars indicate the measurement uncertainty as \pm 1 standard deviation.

Table 1. Isotopic differences between a reference water and water samples in a closed, open and retrofitted bottle that were stored outside the ISCO autosampler during Experiment 1. Isotopic differences are expressed as mean \pm 1 standard deviation.

\begin{tabular}{lrrr}
\hline $\begin{array}{l}\text { Bottle } \\
\text { type }\end{array}$ & $\begin{array}{r}\text { Storage } \\
\text { duration [d] }\end{array}$ & $\Delta \delta^{2} \mathrm{H}[\%$ o $]$ & \multicolumn{1}{c}{$\Delta \delta^{18} \mathrm{O}[\%$ ] $]$} \\
\hline Closed & 24 & $-0.42 \pm 0.27$ & $-0.08 \pm 0.12$ \\
Retrofitted & 24 & $9.05 \pm 0.54$ & $1.63 \pm 0.15$ \\
Open & $12^{*}$ & $100.46 \pm 1.04$ & $21.97 \pm 0.20$ \\
\hline
\end{tabular}

* For the open bottle, the change in isotopic composition between day 0 and day 12 is provided, because the water sample was fully evaporated from the open bottle by day 24 .

we observed isotopic enrichment in both the retrofitted and the open bottle. Enrichment was substantially stronger for the sample in the open bottle (a change of roughly $100 \%$ in $\delta^{2} \mathrm{H}$ and $22 \%$ in $\delta^{18} \mathrm{O}$ within the first $12 \mathrm{~d}$ ) compared to the sample in the retrofitted bottle (a change of $9 \% \circ$ in $\delta^{2} \mathrm{H}$ and $2 \%$ in $\delta^{18} \mathrm{O}$ over $24 \mathrm{~d}$ ). We sampled the open bottle already on day 12 of the experiment because we had observed substantial evaporation by then. At the end of the monitoring period (day 24), the water from the open bottle had evaporated completely, while the loss of water volume was small in the retrofitted bottle (Fig. 3).

The $\delta^{2} \mathrm{H}$ values of the water samples from inside the ISCO autosampler show that evaporative fractionation differed between samples from open and retrofitted bottles and also varied with storage duration (Fig. $2 b$ and c). The isotopic differences (Eq. 4) were generally smaller for samples in retrofitted bottles compared to those in the open bottles. For

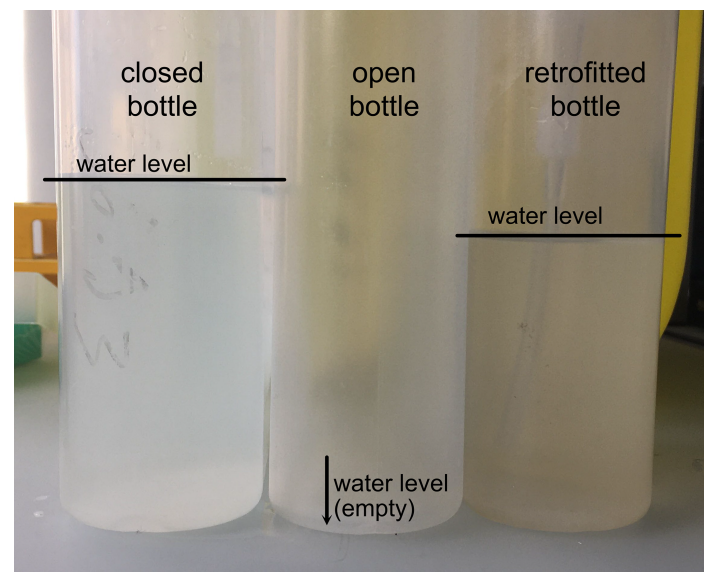

Figure 3. Water levels in the three bottles stored outside of the autosampler on day 24 of Experiment 1. The water level in the closed bottle is identical to the water level in all three bottles at the start of the experiment. By the end of the experiment the water level in the retrofitted bottle had only decreased slightly, while the water from the open bottle was completely evaporated after approximately $12 \mathrm{~d}$.

$\delta^{2} \mathrm{H}$, the isotopic differences $\left(\Delta \delta^{2} \mathrm{H}\right)$ in the retrofitted bottles were mostly close to $0 \%$ independent of storage duration, while the isotopic enrichment in the open bottles ranged up to $5 \%$ (Fig. 2b). For $\delta^{18} \mathrm{O}$, we obtained less clear fractionation signals, and while the enrichment was always greater in samples of open bottles compared to those in retrofitted bottles, we also observed isotopic depletion of up to $-0.3 \%$ for samples in retrofitted bottles that were filled early on in the 
experiment (data for $\delta^{18} \mathrm{O}$ are presented in Fig. S1 in the Supplement).

Water samples filled on and before day 14 of Experiment 1, i.e., samples with 10 or more days of storage time, showed substantially larger $\Delta \delta^{2} \mathrm{H}$ values in the open bottles than in the retrofitted bottles: samples in open bottles experienced stronger enrichment (Fig. 2b). Conversely, samples collected on day 16 and later, and thus stored for $8 \mathrm{~d}$ or less, experienced little or no evaporative fractionation, independent of the bottle type (i.e., $\Delta \delta^{2} \mathrm{H}$ was not significantly different from zero). This decrease in evaporative fractionation in the later samples may have been caused by the increase in relative humidity to approximately $90 \%$ on day 10 and $100 \%$ on day 12 inside the autosampler housing (Fig. 2a). Surprisingly, samples filled on days 10 and 12 showed stronger enrichment than those filled on adjacent days, both for open and retrofitted bottles. Because this isotope effect occurred in both bottle types it cannot be attributed to a specific process; it may have been related to interferences in the isotope analyzer.

Figure 2c compares the $\Delta \delta^{2} \mathrm{H}$ values of samples from open and retrofitted bottles against the average relative humidity inside the ISCO autosampler. While the change in relative humidity inside the ISCO autosampler did not seem to affect the samples in the retrofitted bottles, we obtained a nearly linear relationship for the open bottles indicating a $2.8 \%$ enrichment per $10 \%$ decrease in relative humidity $(p<0.005)$. Such a relationship is expected, because the vapor phase in the open bottle is in exchange with the vapor phase inside the ISCO housing, and evaporation from the liquid phase is generally faster when water vapor concentrations in the gas phase are lower (assuming constant temperature). Due to the much smaller contact area between the liquid and vapor phases in the retrofitted ISCO bottles, vapor exchange was reduced and evaporation from the liquid sample was much smaller (even when relative humidities were below $90 \%$ inside the autosampler housing; Fig. 2c). Retrofitting made little difference at $\approx 100 \%$ humidity, when vapor pressure deficits, and thus evaporation rates, were minimal. Relative humidity outside the ISCO autosampler and temperatures inside and outside the ISCO autosampler remained nearly constant throughout the monitoring period, so their relationship with the observed isotopic composition could not be identified and their effect on evaporative fractionation in this laboratory experiment could not be assessed.

In spite of the high temperatures and low relative humidity inside the ISCO autosampler, the observed fractionation effects during Experiment 1 were not large. This may have been due to some limitations in the setup. For one, we did not use the built-in peristaltic pump of the ISCO system to fill our samples, which follows the protocol for collecting precipitation samples but is not suitable for streamwater grab sampling. In case of streamwater sampling, the pump is used and the tubing between the sampling location and pump is flushed with air before sampling. This process likely results in an intake of air into the ISCO and consequently enhanced vapor exchange with the surrounding atmosphere, which may enhance isotopic fractionation of the collected water sample. In addition, we could not measure the water volumes in the sample bottles at the time of filling and at the end of the experiment because we did not want to open the ISCO autosampler during the experiment period. While we took care to fill exactly $400 \mathrm{~mL}$ reference water into each sample bottle through the distributor arm, we cannot exclude that some spillage occurred during the filling procedure or that some residual water remained in the sampling tube. It is therefore not possible to assess the exact amount of sample volume that was lost due to evaporation.

\subsection{Assessing the effect of evaporative fractionation and mixing: Experiment 2}

Ambient conditions during Experiment 2 were colder and more humid compared to Experiment 1 and substantially more variable. Outside the ISCO autosamplers, air temperature (mean \pm standard deviation) was $13.3 \pm 6.2^{\circ} \mathrm{C}$ in the outdoor setting and $18.6 \pm 4.7^{\circ} \mathrm{C}$ indoors, while relative humidity was $73.5 \pm 23.0 \%$ outdoors with distinct daily fluctuations and $44.8 \pm 8.9 \%$ indoors (values of temperature and relative humidity measured outside the ISCO autosamplers are not shown but are provided in the Supplement). Temperature and relative humidity measured inside the autosampler housings exhibited similar but damped diurnal patterns (see Fig. $4 a$ and $b$ ). The temperature and relative humidity inside the outdoor ISCO were $16.7 \pm 6.7^{\circ} \mathrm{C}$ and $86.0 \pm 13.6 \%$, respectively. For the indoor ISCO autosampler, the respective values were $18.2 \pm 2.9^{\circ} \mathrm{C}$ and $96.7 \pm 2.7 \%$. In contrast to Experiment 1, the relative humidity inside the autosampler housing did not increase gradually to $100 \%$ over several days but remained high throughout the experiment, probably because all sample bottles were filled from the start, instead of successively as in Experiment 1.

The changes in isotopic composition, $\Delta \delta^{2} \mathrm{H}_{\text {RefA }}$ and $\Delta \delta^{2} \mathrm{H}_{\text {RefB }}$, were calculated following Eq. (4) with sample being RefA or RefB water in the open or retrofitted bottles and reference being RefA or RefB water in the closed bottles. We observed no significant change in the isotopic composition of samples in retrofitted bottles (both $\Delta \delta^{2} \mathrm{H}_{\text {RefA }}$ and $\Delta \delta^{2} \mathrm{H}_{\mathrm{RefB}} \approx 0 \%$, red filled markers in Fig. $4 \mathrm{c}-\mathrm{f}$; results for $\Delta \delta^{18} \mathrm{O}$ were similar, see Fig. S2), whereas the isotopic composition of samples in open bottles changed over the course of the experiment by up to $10 \%$ o (blue open markers in Fig. 4c-f). The observed isotopic differences of samples in open bottles were more pronounced for smaller sample volumes (comparison of circles and diamonds in Fig. 4cf). It was also larger in the outdoor setting compared to indoor conditions (comparison of Fig. 4c and e with Fig. 4d and $\mathrm{f}$ ), even though the average temperature was lower in the outdoor setting. This may indicate that the average temperature is less important for causing isotope effects than the 

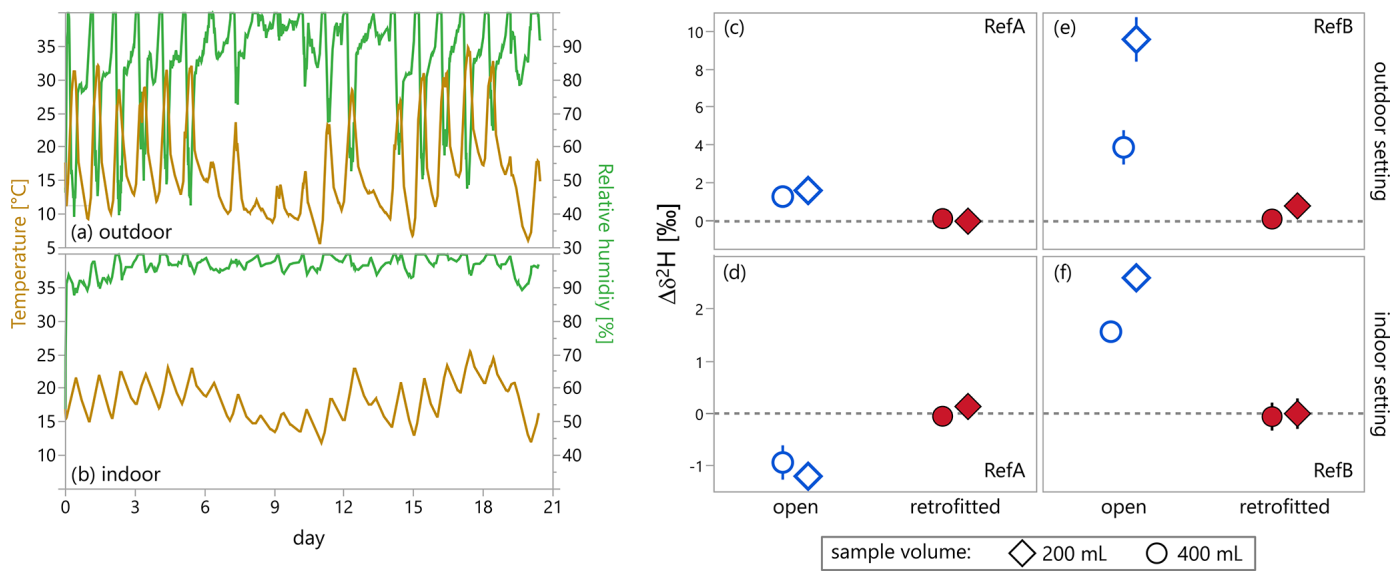

Figure 4. (a, b) Temperature (yellow) and relative humidity (green) measured inside the ISCO autosamplers that were located outdoors (a) and indoors (b) over the $21 \mathrm{~d}$ of Experiment 2. (c-f) Mean change in isotopic composition of samples relative to the reference waters. Each data point is calculated from the three replicates of each combination of the two reference waters (RefA vs. RefB), the two sample volumes $(200 \mathrm{~mL}$ vs. $400 \mathrm{~mL}$ ), and the two bottle types (open vs. retrofitted with evaporation protection). Please note that the $y$-axis scales differ between the upper (c, e) and lower (d, f) panels. Error bars denote standard errors of the three replicates of each condition and account for measurement uncertainty and the standard error of the sample means.

magnitude of the temperature fluctuations that may trigger gas volume exchanges. In contrast to Experiment 1 (ventilated chamber), Experiment 2 was characterized by significant daily temperature fluctuations $\left(20^{\circ} \mathrm{C}\right.$ and more inside the autosampler that was situated outdoors; Fig. 4a). During the daytime when the air temperature increased, the air inside the autosampler expanded and some of the (moist) air was pushed out of the device; when temperatures dropped (at night), the opposite happened: the air inside the autosampler contracted and sucked in fresh air from outside. This "sampler breathing" probably happened on a daily basis, resulting in a greater air exchange with the outside, which in turn may have reduced the humidity inside the autosampler and resulted in more evaporation. In addition, the greater potential for wind-driven ventilation of the autosampler located outdoors may also have enhanced evaporative fractionation effects in the open sample bottles. Samples which underwent a stronger change in isotopic composition also experienced a greater loss of sample volume between the start and end of the experiment. We observed a larger decrease in sample volumes in open bottles compared to the retrofitted sample bottles, a larger decrease in sample volumes in the outdoor setting compared to the indoor setting, and a larger relative decrease in the $200 \mathrm{~mL}$ samples compared to the $400 \mathrm{~mL}$ samples (see Fig. S3).

In the outdoor setting, the samples in the open bottles became isotopically heavier, with larger changes observed in the $200 \mathrm{~mL}$ samples than in the $400 \mathrm{~mL}$ samples (e.g., $\delta^{2} \mathrm{H}$ in RefB water increased by $9.6 \%$ and $3.9 \%$ in 200 and $400 \mathrm{~mL}$ samples, respectively; Fig. 4e), likely due to evaporative fractionation. For the open bottles in the indoor setting, however, RefA samples became isotopically lighter by about $1 \%$ in $\delta^{2} \mathrm{H}(-1.2 \%$ and $-0.9 \%$ for 200 and $400 \mathrm{~mL}$, respectively; Fig. 4e), while RefB samples became roughly $2 \%$ heavier $(2.6 \%$ and $1.6 \%$ for 200 and $400 \mathrm{~mL}$, respectively; Fig. 4f). The isotopic lightening of RefA samples may be explained by mixing in the vapor phase of isotopically heavier RefA water with isotopically lighter RefB water and subsequent condensation in both samples. This isotopic exchange should make RefA samples isotopically lighter and RefB samples isotopically heavier, in addition to any isotopic fractionation due to net evaporative losses from both samples. Thus, a large part of the observed enrichment in RefB water in the indoor setting may have been due to isotopic exchange with the heavier RefA water, in addition to any evaporative fractionation. A likely reason why the mixing effect was only visible in the indoor setting may be that evaporation was smaller compared with the outdoor setting; the greater evaporative losses (and thus evaporative fractionation) in the outdoor setting may have overprinted the vapor mixing effect. In either case, mixing and/or evaporative fractionation only affected the isotopic composition in the open sample bottles, while no measurable effect was observed in samples from the retrofitted bottles.

We can quantify the isotope effects due to mixing and evaporative fractionation in the different settings under the assumption that (a) evaporative fractionation and mixing have additive effects, (b) the per mil change due to evaporative fractionation is the same for RefA and $\operatorname{RefB}$ waters, and (c) mixing has an exactly inverse effect on the two waters (i.e., it results in the same degree of isotopic depletion in the heavier RefA water and enrichment in the lighter RefB water):

$m_{\text {RefA }}+f=\Delta \delta^{2} \mathrm{H}_{\text {RefA }}$, 


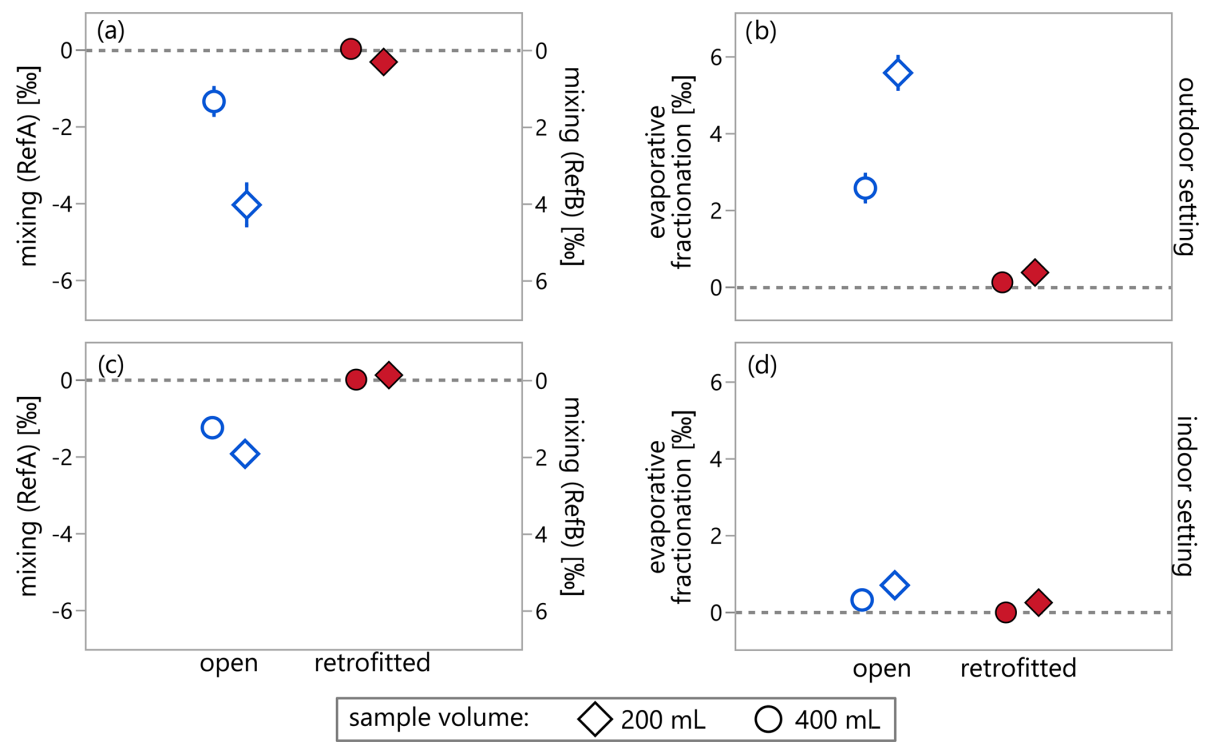

Figure 5. A comparison of the isotope effects due to mixing $(\mathbf{a}, \mathbf{c})$ and evaporative fractionation $(\mathbf{b}, \mathbf{d})$ in water samples stored outdoors $(\mathbf{a}, \mathbf{b})$ and indoors (c, d) during Experiment 2. Both mixing and evaporative fractionation effects are small in samples from the retrofitted bottles (filled red markers) and larger in samples from the open bottles (open blue markers). In addition, the isotope effects were larger for the $200 \mathrm{~mL}$ samples (diamonds) than for the $400 \mathrm{~mL}$ samples (circles). Error bars indicate standard errors determined from the three replicates of each combination of the two reference waters (RefA vs. RefB), the two sample volumes ( $200 \mathrm{~mL} v \mathrm{ss} .400 \mathrm{~mL}$ ), and two bottle types (open vs. retrofitted with evaporation protection), and they account for measurement uncertainty and the standard error of the sample means.

$m_{\mathrm{RefB}}+f=\Delta \delta^{2} \mathrm{H}_{\mathrm{RefB}}$,

$m_{\mathrm{RefA}}=-m_{\mathrm{RefB}}$

where mixing-induced isotopic change is denoted by $m$ for RefA and RefB waters, and the change in isotopic composition due to evaporative fractionation is denoted by $f$.

The results of this analysis are illustrated in Fig. 5 for deuterium, confirming that isotope effects due to mixing and evaporation are small in samples from the retrofitted bottles (red filled markers). In the open bottles (blue open markers), the isotope effects due to evaporative fractionation were 1.5 to 2 times larger than the isotopic change due to mixing in the outdoor setting, but fractionation was less important than mixing in the indoor setting. Both the mixing- and fractionation-induced isotope effects were roughly twice as large in the $200 \mathrm{~mL}$ samples as in the $400 \mathrm{~mL}$ samples (diamonds vs. circles, respectively). Applying Eqs. (5)-(7) to oxygen-18 yielded similar results (see Fig. S4).

In summary, the results of Experiment 2 confirmed the findings from Experiment 1 that the retrofitted ISCO bottles efficiently protected the collected water samples from undergoing isotopic changes due to both evaporative fractionation and vapor mixing.

\subsection{Evaluation of the evaporation protection in the field}

During the field experiment (Experiment 3, October 2015 to June 2019), we observed distinct seasonality in air tem- perature but no seasonal pattern in relative humidity at both field sites and slightly higher temperatures and humidity at the EIN site (Fig. 6). At both field sites, the vapor pressure deficit (VPD), which is strongly correlated with air temperature, peaked around June and July and was lowest in December and January. Because these climatic variables exhibited very similar behavior at both field sites, we decided to pool the isotope data sets from both sites for analysis.

The isotope data from 8 March 2016 were excluded from this analysis because the water samples in the retrofitted bottles were isotopically lighter than the reference water (e.g. $\Delta \delta^{2} \mathrm{H}$ ranged from $-4.7 \%$ o to $-3.5 \%$ ) for unknown reasons. In addition, we removed the data points from 14 February 2017 from our analysis because of an anomalous $\delta^{18} \mathrm{O}$ measurement of the water sample from the retrofitted bottle at the ERL site.

Experiment 3 resulted in 244 usable samples (i.e., 61 samples per site and bottle type) for which the storage duration varied between 12 and $23 \mathrm{~d}$. The isotopic differences of the samples in open bottles relative to the reference water exhibited substantial scatter, with values between $-2 \%$ and $+3.5 \%$, but the average isotopic differences (mean \pm 1 standard error were $1.45 \pm 0.22 \%$ for $\Delta \delta^{2} \mathrm{H}$ and $0.27 \pm 0.05 \%$ for $\Delta \delta^{18} \mathrm{O}$ and thus deviated statistically significantly from zero. Conversely, when the retrofitted bottles were used, the isotopic differences were not statistically significantly larger than zero, i.e., $0.10 \pm 0.11 \%$ for $\Delta \delta^{2} \mathrm{H}$ and $0.05 \pm 0.03 \%$ o for $\Delta \delta^{18} \mathrm{O}$. Figures 7 and S5 show that the isotopic differences of the samples in open bottles rel- 


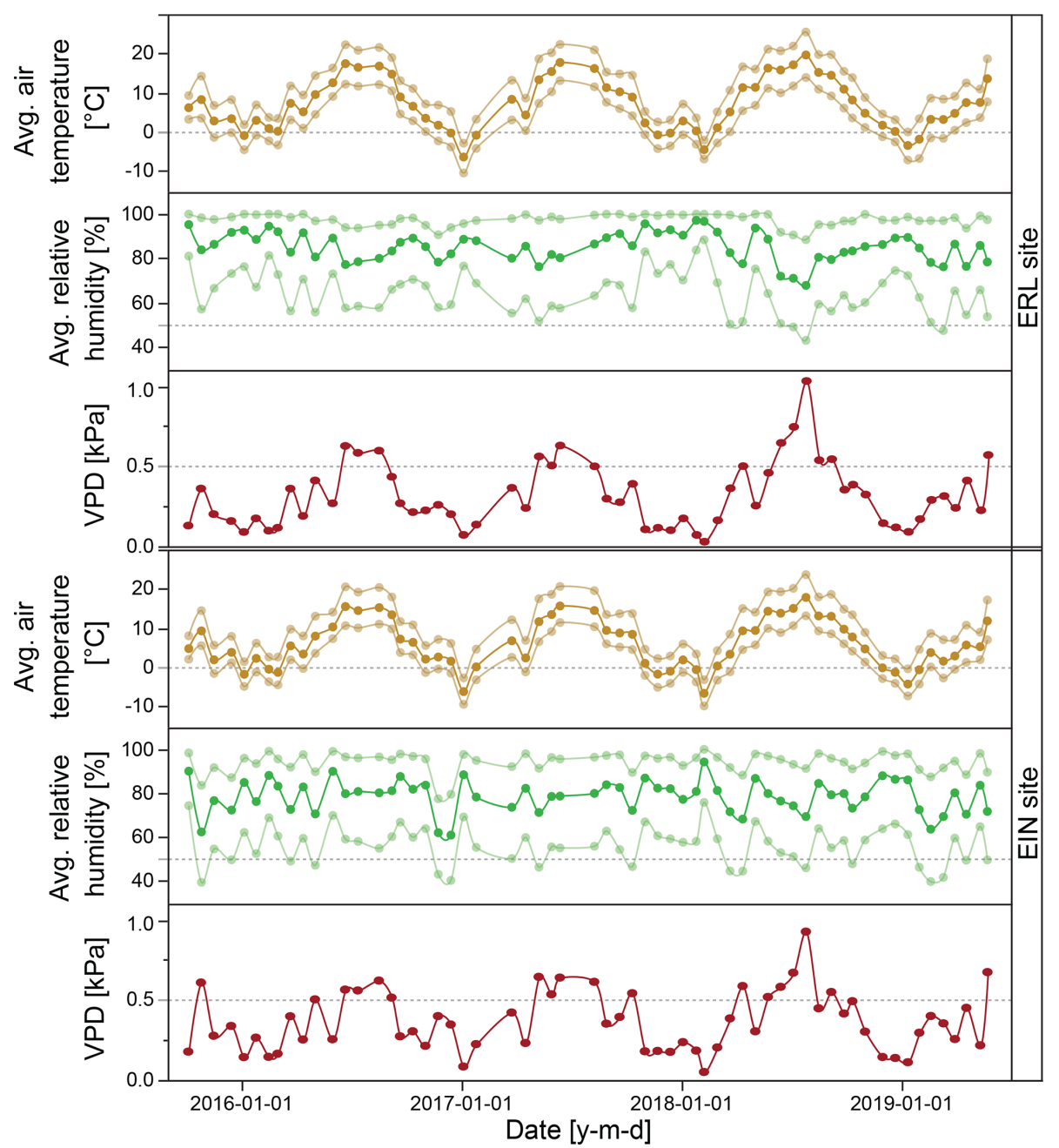

Figure 6. Mean, minimum, and maximum values of air temperature and relative humidity, as well as vapor pressure deficit (VPD), averaged over 2-3-week storage periods during Experiment 3 at the two field sites EIN and ERL. Dashed horizontal lines in each panel indicate $0{ }^{\circ} \mathrm{C}$ air temperature, $50 \%$ relative humidity, and $0.5 \mathrm{kPa}$ VPD for easier comparison between sites.

ative to the reference water were positively correlated with average air temperature and thus with VPD. Pearson correlation coefficients between air temperature (average, minimum and maximum) and $\Delta \delta^{2} \mathrm{H}$ were $r>0.70(p<0.001)$ and $r>0.60(p<0.001)$ for $\Delta \delta^{18} \mathrm{O}$. For VPD, the correlation coefficients were $r>0.56(p<0.001)$ for both isotopes. No statistically significant relationships were evident for the samples from the retrofitted bottles $(r<0.17, p>0.1$ for both isotopes; see also the red data points in Figs. 7 and S5). Similarly, higher climatic variability at our field sites (represented by the maximum changes in air temperate and relative humidity) was associated with larger isotopic differences only for the open bottles (the relationship was statistically significant only for the change in air temperature, with $r>0.40$ and $p<0.0001$ for both isotopes; Figs. 8 and S6).

Overall, our results indicate that the retrofitted sample bottles significantly reduced isotopic fractionation compared to the open sample bottles when deployed over 2-3-week pe- riods under the ambient climatic conditions at our two field sites.

\section{Practical implications}

In the three experiments presented above, we assessed how storage duration, temperature and humidity fluctuations, and sample volume influenced isotopic shifts due to evaporative fractionation and vapor mixing in samples stored inside the ISCO autosampler. In all three experiments we found that the observed change in isotopic composition was substantially smaller in samples stored in bottles that were retrofitted for evaporation protection.

We can use the relationship between isotopic fractionation and air temperature from Experiment 3 to estimate the expected isotopic change in the water samples collected in the laboratory during Experiment 1 . If we apply the linear re- 


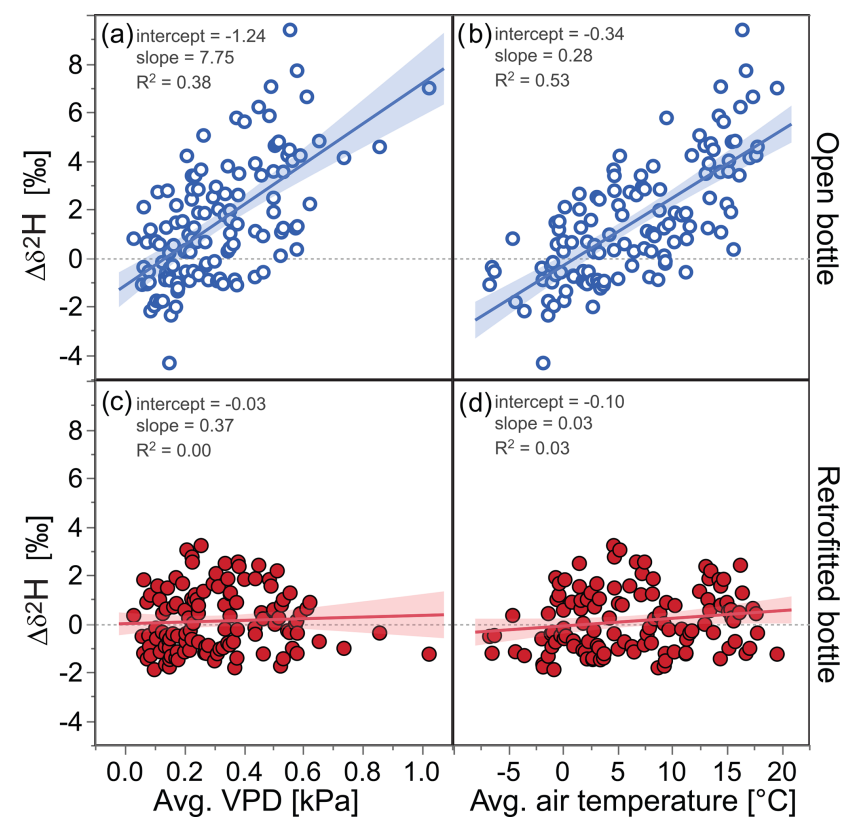

Figure 7. Deuterium differences $\left(\Delta \delta^{2} \mathrm{H}\right)$ in samples stored in open and retrofitted ISCO bottles relative to a reference water and their relationships with the average vapor pressure deficits (VPDs) and the average air temperatures during the respective storage periods at the EIN and ERL sites. Samples in open bottles (open blue circles) show a substantial isotopic enrichment with higher VPD and air temperature, whereas samples in retrofitted bottles (filled red circles) do not indicate a systematic fractionation effect. No relationship with relative humidity was found. The uncertainties of the individual $\Delta \delta^{2} \mathrm{H}$ values were on average $0.52 \%$; linear regression fits are indicated by solid lines, as well as slope, intercept, and $R^{2}$ values; the shaded areas represent the $95 \%$ confidence intervals of the fitted lines.

gression slopes shown in Fig. $7 \mathrm{~b}$ to calculate the expected isotopic difference in the samples in open bottles at the average air temperature of $35^{\circ} \mathrm{C}$ maintained during Experiment 1 , we obtain $\Delta \delta^{2} \mathrm{H}=9.4 \pm 1.1 \%$ ( \pm 1 standard error) and $\Delta \delta^{18} \mathrm{O}=1.6 \pm 0.3 \%$. These estimates are substantially larger than the measured differences after $24 \mathrm{~d}$ of Experiment 1 (i.e., $\Delta \delta^{2} \mathrm{H}=5 \%$ and $\Delta \delta^{18} \mathrm{O}=1 \%$; Sect. 3.1). The larger isotopic change observed during the field deployment of Experiment 3 may be attributed to more variable climatic conditions (e.g., due to diurnal temperate variations) causing "sampler breathing" and possibly also to variable ventilation by wind, whereas during Experiment 1 the sampler was placed in a windless chamber with less variable temperature and relative humidity. This hypothesis is supported by the results from Experiment 2, where isotopic differences were larger in the open bottles in the outdoor setting compared to the indoor setting (e.g., $\Delta \delta^{2} \mathrm{H}$ was $3.9 \%$ vs. $1.6 \%$, respectively, for the $400 \mathrm{~mL}$ RefB samples in open bottles). Larger temperature and humidity contrasts due to diurnal fluctuations in outdoor conditions may have resulted in repeated evaporation and condensation inside the autosampler hous-

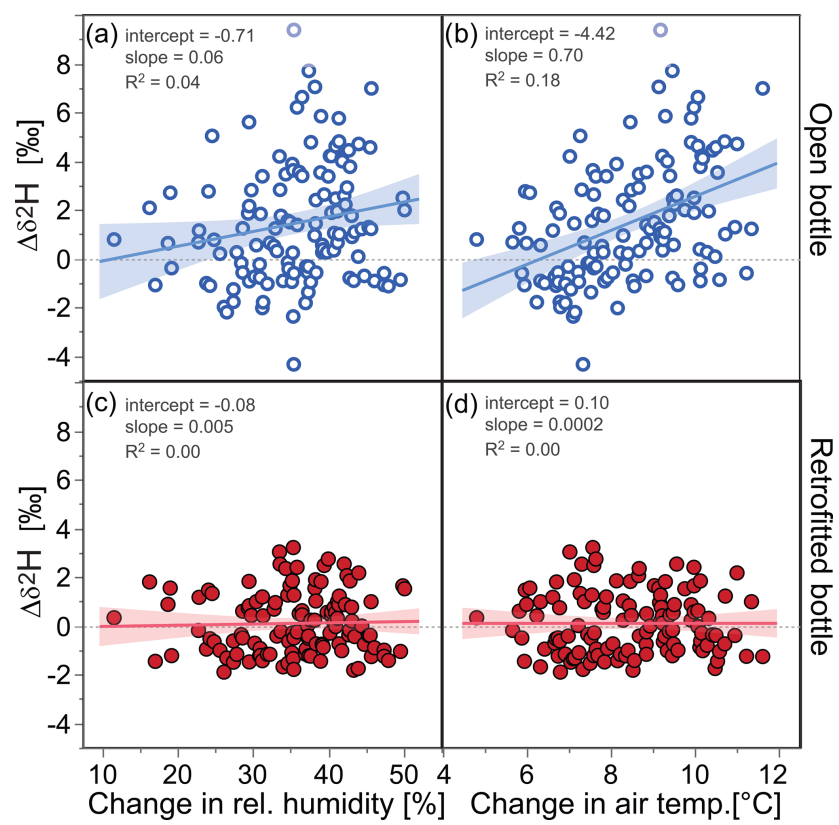

Figure 8. Deuterium differences $\left(\Delta \delta^{2} \mathrm{H}\right)$ in samples stored in open and retrofitted ISCO bottles relative to a reference water and their relationships with the maximum changes in relative humidity and air temperature within the respective storage periods at the EIN and ERL sites. Large changes in relative humidity resulted in some isotopic enrichment in samples stored in open bottles (open blue circles) but not in the retrofitted bottles (filled red circles). Samples in open bottles showed the strongest isotopic enrichment when temperature contrasts were large $\left(>10^{\circ} \mathrm{C}\right)$, whereas samples in retrofitted bottles seemed to be unaffected by temperature changes. The relationship between the change in air temperature and $\Delta \delta^{2} \mathrm{H}$ of samples in open bottles was statistically significant $(r=0.42$, $p<0.0001)$. The uncertainties of the individual $\Delta \delta^{2} \mathrm{H}$ values were on average $0.52 \%$; linear regression fits are indicated by solid lines, as well as slope, intercept, and $R^{2}$ values; the shaded areas represent the $95 \%$ confidence intervals of the fitted lines.

ing and in enhanced vapor exchange between the sample bottles and the outside atmosphere ("sampler breathing").

Our evaporation protection reduced the contact area between the water surface in the sample bottle and the atmosphere inside the ISCO autosampler by a factor of approximately 5500 (comparing the cross-sectional area of the bottle to that of the silicone tube attached to the syringe) and also the area for diffusion of vapor through the bottle opening by a factor of approximately 1300 (comparing the area of the bottle opening to the cross-sectional area of the silicone tube). Consequently, isotopic fractionation and mixing should be substantially reduced in samples in retrofitted bottles compared to those in open sample bottles. However, because the syringe housing does not entirely seal the ISCO sample bottle (because air needs to be released when water samples are introduced into the bottle), some vapor exchange may still occur between the sample bottle and the atmosphere inside of the autosampler housing. This vapor exchange will 
likely be stronger if air temperature is high and relative humidity inside the autosampler housing is low (Experiment 1). Experiment 2 also suggested that strong diurnal variations or windy conditions will also increase vapor exchange and consequently evaporative fractionation. In central European climates, such conditions may occur during extremely dry and warm summer days so that automatically collected water samples should be retrieved after less than $24 \mathrm{~d}$ if possible. However, Experiment 1 showed that in the absence of wind, the relative humidity inside the autosampler can build up over time, even if the relative humidity outside is very low.

We furthermore showed that in open bottles, $400 \mathrm{~mL}$ samples exhibited smaller isotope effects than $200 \mathrm{~mL}$ samples, simply because the ratio between the water volume affected by mixing and fractionation (i.e., the uppermost water layer that is in exchange with the atmosphere) and the total sample volume is 2 times smaller for the $400 \mathrm{~mL}$ sample than for the $200 \mathrm{~mL}$ sample (Experiment 2). We therefore recommend that streamwater samples collected with our evaporation protection method should comprise at least $400 \mathrm{~mL}$ (but note that due to the narrow silicone tube, care has to be taken to not exceed a filling rate of approximately $100 \mathrm{~mL} \mathrm{~min}^{-1}$ ). When collecting precipitation samples, larger sample volumes can be achieved by using larger funnels; for example, $1 \mathrm{~mm}$ of rain collected with a $45 \mathrm{~cm}$ diameter funnel results in approximately $160 \mathrm{~mL}$ sample volume, while a $20 \mathrm{~cm}$ diameter funnel would only yield around $30 \mathrm{~mL}$. Control samples with known isotopic composition in open, retrofitted, and closed bottles, placed in the autosampler for the entire storage duration, should be used to monitor composite isotope effects and to allow for a retrospective quality assessment of the automatically collected samples.

While we have discussed the performance of the retrofitted ISCO $1 \mathrm{~L}$ sample bottles with respect to stable water isotopes, the new bottle design may also be useful for water quality studies. Experiment 2 showed that evaporation from open sample bottles resulted in reduced water sample volumes, implying evapoconcentration of solutes in the samples. The importance of this effect likely depends on the storage duration and the sample volume and will therefore be greater for small samples and for samples collected early on in the sampling period. Consequently, water quality data from water samples automatically collected in open bottles and stored over periods of days and weeks may not be directly comparable. The results from Experiment 2 suggest that our retrofitted sample bottle may reduce evapoconcentration effects in the water samples. To further adapt the presented evaporation protection for water quality studies, our design could also be combined with a gravitational filtration system (e.g., Kim et al., 2012) added between the syringe outlet and the silicone tubing. However, further studies would be needed to assess this filtration approach in a more systematic manner.

\section{Conclusions}

We tested whether retrofitting the $1 \mathrm{~L}$ sample bottles of the conventional 6712 full-size portable sampler (Teledyne ISCO, Lincoln, USA) with a modified syringe housing and silicone tube reduces evaporative fractionation and vapor mixing in water samples collected for subsequent stable water isotope analysis. Laboratory and field tests under different temperature and humidity conditions showed that water samples in retrofitted bottles were far less altered by evaporative fractionation and vapor mixing than samples stored in conventional open bottles.

The setup described here can likely be adapted without difficulty (e.g., by using a different syringe size) to be compatible with bottles in other autosamplers, such as the Maxx P6L vacuum system (Maxx $\mathrm{GmbH}$, Rangendingen, Germany) or the smaller ISCO $6712 \mathrm{C}$ and $3700 \mathrm{C}$ compact portable samplers (Teledyne ISCO, Lincoln, USA) that use $500 \mathrm{~mL}$ sample bottles. These adapted evaporation protections will require further testing because the observed results partly depend on the size of the air space and thus the buildup of humidity inside the autosampler. Different autosampler designs may also be more or less tightly sealed from the surrounding atmosphere, likely resulting in differing rates of vapor exchange.

Conventional automatic water samplers are generally available in many laboratories, but researchers may be reluctant to use them for isotope studies due to the risk of evaporative fractionation and vapor mixing occurring in the water samples, particularly if sample volumes are small, weather conditions are dry and warm, and/or samples are stored for multiple weeks. We showed that retrofitting 1 L ISCO sample bottles with a modified syringe housing and silicone tube can be a cost-efficient approach to upgrade the 6712 full-size portable sampler so that water samples are protected from isotopic fractionation during storage in the field. This inexpensive and robust method may thus provide a new possibility for water sample collection at remote locations at daily or sub-daily frequencies over periods of up to $24 \mathrm{~d}$.

Data availability. The stable water isotope measurements from the three experiments are provided as Supplement.

Supplement. The supplement related to this article is available online at: https://doi.org/10.5194/hess-24-5821-2020-supplement.

Author contributions. JvF, JLAK, and JWK designed the study. JvF, JLAK, AR, and BS performed the experiments and analyzed the isotope data, JvF, JLAK, and AR analyzed the data sets, and $\mathrm{JvF}$ and JLAK prepared the manuscript with contributions from all co-authors. 
Competing interests. The authors declare that they have no conflict of interest.

Acknowledgements. We wish to thank Nikos Anestis, Stephan Biber, Stefan Boss, Linus Ender, Özden Erden, Joël Frey, Selina Ilchmann, Vincent Marmier, Daniel Meyer, Dominic Schori, and Kari Steiner for their help in the field and in the laboratory and Alessandro Schlumpf and Massimiliano Zappa for their help with the development of the evaporation protection. We are grateful for comments by Niel Michelsen and one anonymous reviewer that helped to improve the manuscript.

Financial support. Julia L. A. Knapp acknowledges support from an ETH Zurich Postdoctoral Fellowship. Jana von Freyberg was partly supported by the Swiss National Science Foundation SNF (grant PR00P2_185931).

Review statement. This paper was edited by Christine Stumpp and reviewed by Nils Michelsen and one anonymous referee.

\section{References}

Allen, R. G., Pereira, L. S., Raes, D., and Smith, M.: Crop evapotranspiration - Guidelines for computing crop water requirements, FAO Irrigation and drainage paper 56, FAO, Rome, 1998.

Angermann, L., Jackisch, C., Allroggen, N., Sprenger, M., Zehe, E., Tronicke, J., Weiler, M., and Blume, T.: Form and function in hillslope hydrology: characterization of subsurface flow based on response observations, Hydrol. Earth Syst. Sci. 21, 3727-3748, https://doi.org/10.5194/hess-21-3727-2017, 2017.

Ankor, M. J., Tyler, J. J., and Hughes, C. E.: Development of an autonomous, monthly and daily, rainfall sampler for isotope research, J. Hydrol., 575, 31-41, https://doi.org/10.1016/j.jhydrol.2019.04.074, 2019.

Berman, E. S. F., Gupta, M., Gabrielli, C., Garland, T., and McDonnell, J. J.: High-frequency field-deployable isotope analyzer for hydrological applications, Water Resour. Res., 45, W10201, https://doi.org/10.1029/2009wr008265, 2009.

Dawson, T. E. and Ehleringer, J. R.: Streamside trees that do not use stream water, Nature, 350, 335-337, https://doi.org/10.1038/350335a0, 1991.

Fischer, B. M. C., van Meerveld, I., and Seibert, J.: Spatial variability in the isotopic composition of rainfall in a small headwater catchment and its effect on hydrograph separation, J. Hydrol., 547, 755-769, https://doi.org/10.1016/j.jhydrol.2017.01.045, 2017.

Gat, J. R., Mook, W. G., and Meijer, H. A.: Environmental Isotopes in the Hydrological Cycle: Principles and Applications, in: Volume II:International Atomic Energy Agency and and United Nations Educational, Scientific and Cultural Organization, available at: http://www-naweb.iaea.org/napc/ ih/IHS_resources_publication_hydroCycle_en.html (last access: 29 November 2020), 2001.

Gröning, M., Lutz, H. O., Roller-Lutz, Z., Kralik, M., Gourcy, L., and Pöltenstein, L.: A simple rain collector preventing wa- ter re-evaporation dedicated for $\delta^{18} \mathrm{O}$ and $\delta^{2} \mathrm{H}$ analysis of cumulative precipitation samples, J. Hydrol., 448-449, 195-200, https://doi.org/10.1016/j.jhydrol.2012.04.041, 2012.

Hartmann, A., Luetscher, M., Wachter, R., Holz, P., Eiche, E., and Neumann, T.: Technical note: GUARD - an automated fluid sampler preventing sample alteration by contamination, evaporation and gas exchange, suitable for remote areas and harsh conditions, Hydrol. Earth Syst. Sci., 22, 4281-4293, https://doi.org/10.5194/hess-22-4281-2018, 2018.

IAEA - International Atomic Energy Agency: A new device for monthly rainfall sampling for GNIP, Water Environment News, available at: https://inis.iaea.org/collection/NCLCollectionStore/ _Public/34/014/34014804.pdf (last access: 29 November 2020), 2002.

IAEA - International Atomic Energy Agency: IAEA/GNIP precipitation sampling guide, available at: http://www-naweb.iaea.org/ napc/ih/documents/other/gnip_manual_v2.02_en_hq.pdf (last access: 29 November 2020), 2014.

Kendall, C. and McDonnell, J. J.: Isotope tracers in catchment hydrology, Elsevier, Amsterdam, New York, 839 pp., 1998.

Kim, H., Bishop, J. K. B., Wood, T. J., and Fung, I. Y.: Autonomous Water Sampling for Long-Term Monitoring of Trace Metals in Remote Environments, Environ. Sci. Technol., 46, 11220-11226, https://doi.org/10.1021/es3006404, 2012.

Klaus, J. and McDonnell, J. J.: Hydrograph separation using stable isotopes: Review and evaluation, J. Hydrol., 505, 47-64, https://doi.org/10.1016/j.jhydrol.2013.09.006, 2013.

Knapp, J. L. A., Neal, C., Schlumpf, A., Neal, M., and Kirchner, J. W.: New water fractions and transit time distributions at Plynlimon, Wales, estimated from stable water isotopes in precipitation and streamflow, Hydrol. Earth Syst. Sci., 23, 4367-4388, https://doi.org/10.5194/hess-23-4367-2019, 2019.

McGuire, K. and McDonnell, J.: Stable Isotope Tracers in Watershed Hydrology, in: Stable Isotopes in Ecology and Environmental Science, Blackwell Publishing Ltd, Malden, MA, 334-374, 2008.

Michelsen, N., van Geldern, R., Rossmann, Y., Bauer, I., Schulz, S., Barth, J. A. C., and Schuth, C.: Comparison of precipitation collectors used in isotope hydrology, Chem. Geol., 488, 171-179, https://doi.org/10.1016/j.chemgeo.2018.04.032, 2018.

Michelsen, N., Laube, G., Friesen, J., Weise, S. M., Bait Said, A. B. A., and Müller, T.: Technical note: A microcontroller-based automatic rain sampler for stable isotope studies, Hydrol. Earth Syst. Sci., 23, 2637-2645, https://doi.org/10.5194/hess-23-26372019, 2019.

Prechsl, U. E., Gilgen, A. K., Kahmen, A., and Buchmann, N.: Reliability and quality of water isotope data collected with a lowbudget rain collector, Rapid Commun. Mass Spectrom., 28, 879885, https://doi.org/10.1002/rcm.6852, 2014.

Rücker, A. B., Zappa, M., Boss, S., and von Freyberg, J.: An optimized snowmelt lysimeter system for monitoring melt rates and collecting samples for stable water isotope analysis, J. Hydrol. Hydromech., 67, 20-31, https://doi.org/10.2478/johh-20180007, 2018.

Rücker, A. B., Boss, S., Kirchner, J. W., and von Freyberg, J.: Monitoring snowpack outflow volumes and their isotopic composition to better understand streamflow generation during rain-on-snow events, Hydrol. Earth Syst. Sci., 23, 2983-3005, https://doi.org/10.5194/hess-23-2983-2019, 2019. 
Shanley, J. B., Pendall, E., Kendall, C., Stevens, L. R., Michel, R. L., Phillips, P. J., Forester, R. M., Naftz, D. L., Liu, B. L., Stern, L., Wolfe, B. B., Chamberlain, C. P., Leavitt, S. W., Heaton, T. H. E., Mayer, B., Cecil, L. D., Lyons, W. B., Katz, B. G., Betancourt, J. L., McKnight, D. M., Blum, J. D., Edwards, T. W. D., House, H. R., Ito, E., Aravena, R. O., and Whelan, J. F.: Chapter 22 - Isotopes as Indicators of Environmental Change, in: Isotope Tracers in Catchment Hydrology, edited by: Kendall, C. and McDonnell, J. J., Elsevier, Amsterdam, 761-816, 1998.

Terzer, S., Wassenaar, L. I., Douence, C., and Araguas-Araguas, L.: An assessment of the isotopic $\left({ }^{2} \mathrm{H} /{ }^{18} \mathrm{O}\right)$ integrity of water samples collected and stored by unattended precipitation totalizers, in: EGU General Assembly, 1 April 2016, Vienna, Austria, 2016. von Freyberg, J., Studer, B., Rinderer, M., and Kirchner, J. W.: Studying catchment storm response using event- and pre-event-water volumes as fractions of precipitation rather than discharge, Hydrol. Earth Syst. Sci., 22, 5847-5865, https://doi.org/10.5194/hess-22-5847-2018, 2018.

Wang, L., von Freyberg, J., van Meerveld, I., Seibert, J., and Kirchner, J. W.: What is the best time to take stream isotope samples for event-based model calibration?, J. Hydrol., 577, 123950, https://doi.org/10.1016/j.jhydrol.2019.123950, 2019.

Williams, M. R., Lartey, J. L., and Sanders, L. L.: Isotopic $\left(\delta^{18} \mathrm{O}\right.$ and $\left.\delta^{2} \mathrm{H}\right)$ Integrity of Water Samples Collected and Stored by Automatic Samplers, Agr. Environ. Lett., 3, 180009, https://doi.org/10.2134/ael2018.02.0009, 2018. 